\title{
A resident's perspective
}

\section{Rami Elias, BHSc, MD}

Chief Urology Resident, Division of Urology, McMaster University, Hamilton, ON

Cite as: Can Urol Assoc J 2015;9(3-4):87. http://dx.doi.org/10.5489/cuai.2865

Published online April 13, 2015.

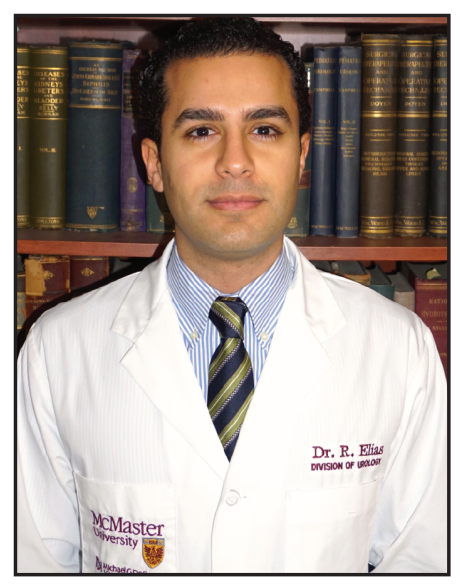

$\mathrm{T}$ he Canadian Urology Association (CUA) has played a pivotal role in enhancing my experience as a urology trainee.

From an academic perspective, the endorsed guidelines and consensus statements published in CUAJ have provided me with a strong framework for evidence-based decision-making. The Canadian Senior Urology Residents' meeting held in St. John's, Newfoundland last year gave me the opportunity to collaborate with colleagues across the country, while completing a comprehensive urodynamic course.

Of particular importance was the resident exchange program with the Urological Society of Australia and New Zealand (USANZ), in which I participated in a weeklong review course in Adelaide, Australia. This yearly event includes an educational component covering basic science concepts and clinical management strategies. I observed the simulated practice OSCEs held for their senior residents, examinations quite similar to the Canadian QUEST experience in Kingston, Ontario. Compared to the Canadian QUEST, board examinations in Australia are structured differently, with a more intricate written component.

During social events, I gained insight into their rigorous urologic training. A newly implemented program in Australia has shortened their residency period to 5 years with a focus on surgical proficiency during the latter stages. Trainees are also assigned to hospitals as opposed to university-based positions. Interestingly enough, there is a concern among graduating residents in finding employment in more populated urban centres after their training. Overall, I found many parallels between the Australian and Canadian systems.

I want to acknowledge the CUA for its continued support of Canadian residents and I encourage others to take advantages of these opportunities.

Competing interests: Dr. Elias declares no competing financial or personal interests.

Correspondence: Dr. Rami Elias, Division of Urology, McMaster Urology, Hamilton, ON; rami.elias@medportal.ca 